\title{
Sección

\section{Morales Gamboa, Abelardo, 2007, La diáspora de la posguerra: regionalismo de los migrantes y dinámicas territoriales en América Central, FLACSO, Costa Rica.}

E ste libro trata sobre los efectos sociales y territoriales de las migraciones de trabajadores y trabajadoras, en la región de América Central, durante la etapa posterior a la crisis política y a los conflictos armados, entre 1990 y 2005. Constituidas como uno de los ejes de las transformaciones económicas, sociales y culturales de la posguerra fría en Centroamérica, las migraciones son analizadas como una de las dimensiones que producen una regionalidad fragmentada. El ajuste de los mercados de trabajo, la flexibilización laboral y la declinación del empleo formal condujeron a la adopción de una variedad de estrategias de sobrevivencia y, como resultado de ellas, a la transnacionalización de las lógicas de reproducción social.

Para Morales Gamboa, el regionalismo es entendido como un proceso de cohesión socio-económica, políticay organizacional de construcción regional. La regionalidad proporciona una comprensión sobre el estado y las fases de la regionalización, dentro de la región de países comprendida por el istmo geográfico de América Central.

Con las siguientes preguntas, Morales Gamboa orientó su investigación:

- ¿Cómo se manifiestan las migraciones intrarregionales dentro de la dinámica territorial centroamericana?

- ¿Cuáles son las características y los cambios de las migraciones en las diferentes etapas del regionalismo y cuál ha sido su evolución histórica?
- ¿Cuáles son las características y las manifestaciones socio-territoriales de las migraciones en la etapa de transnacionalización de la fuerza de trabajo?

- ¿Cuáles efectos tiene la migración sobre la regionalidad, sobre el nuevo regionalismo y sobre las dimensiones sociales y políticas de la ciudadanía?

El estudio se desarrolla en cuatro dimensiones: la primera se ocupa de vínculos entre las migraciones intrarregionales y la construcción regional; la segunda explora la formación de un sistema regional de fuerza de trabajo migrante producido por la articulación entre las migraciones intrarregionales y otros desplazamientos -internos y extra-regionales-; la tercera analiza la interdependencia territorial tejida por las migraciones. Finalmente, la cuarta, trata sobre la cohesión social y territorial que surge como una nueva arena para la ciudadanía regional.

Morales Gamboa analiza las migraciones en el contexto de dos procesos regionales: (a) el de la transición sociopolítica del autoritarismo hacia la democracia y la lucha por la ciudadanía y, (b) el de los efectos de la globalización, expresados en los ajustes, la apertura y privatización de la economía, así como en los cambios en los mercados de trabajo de las sociedades centroamericanas.

Las características de las migraciones son explicadas por Morales Gamboa a partir de los siguientes variables: 
(a) su relación con las nuevas dinámicas espaciales, (b) el perfil de los sujetos involucrados y (c) el tipo de encadenamientos que se producen entre los distintos movimientos y situaciones espaciales. Como resultado de la interacción migratoria se estudian tres realidades socio-espaciales: (a) la aparición de enclaves de fuerza de trabajo migrante, (b) los espacios transfronterizos y (c) el espacio urbano; todas ellas como parte de una división y fragmentación territorial entre enclaves económicos y enclaves laborales.

Para Morales Gamboa, los diversos tipos de migración se han conectado mediante la creación de una oferta flexible de empleo para mercados laborales diversificados sectorial y territorialmente, y segmentados en razón de la competencia económica, de los mecanismos de regulación y de los estigmas culturales sobre los oficios laborales de migrantes y trabajadores locales. Esos encadenamientos son notorios según un conjunto de interacciones territoriales a diferente escala, y produce una fragmentación espacial, una competencia entre localidades y el deterioro de la cohesión territorial. Eso genera un debilitamiento de la regionalidad centroamericana.

La transnacionalización de las estrategias de reproducción social, entre ellas las migraciones, impone, argumenta Morales Gamboa, una contradicción a la función social del sujeto migrante: de una parte, éste se integra de forma precaria a la fuerza laboral y se convierte en un generador de ingreso por la vía de las remesas, pero, por otra parte, queda excluido socialmente por las condiciones mismas de su inserción laboral, por su deshabilitación jurídica para el reclamo de derechos formales, además de la estigmatización social, del rechazo social o xenofobia social e institucional.

A pesar de la centralidad de las migraciones en el orden socioeconómico regional, su existencia plantea una ruptura con el orden normativo y con las formas de regulación de la vida social. Además, deja al descubierto nuevas contradicciones y conflictos en la esfera de la ciudadanía. Aparte de las limitaciones en las virtudes de la justicia, la igualdad y la libertad, esa ruptura se expresa en la aplicación de políticas de inmigración, basadas en criterios de la seguridad nacional y distanciadas de las normas internacionales de protección a las personas migrantes. Esa es la expresión jurídica de las fracturas de la regionalidad: entre la democracia como mecanismo de gobierno y la democracia ejercida como sistema de derechos; entre los principios y la práctica de la ciudadanía; entre la vida social y el territorio; entre el estado nacional y las lógicas de reproducción social.

En resumen, expone Morales Gamboa, la combinación entre la globalización económica y la transnacionalización de la vida social se ha traducido en un debilitamiento de la cohesión regional en Centroamérica. Si bien las migraciones producen una nueva interdependencia social y territorial, ésta produce también nuevas fragmentaciones sociales, culturales y políticas que neutralizan los avances en la construcción de una nueva regionalidad. Esas fragmentaciones son fuertes limitantes para la construcción de la ciudadanía, pues ellas derivan en una mayor precarización social y jurídica o en su extremo: la desciudadanización (la pérdida o negación de la condición de la ciudadanía para la persona migrante).

Ese proceso no ha acabado en Centroamérica, sostiene Morales Gamboa. Un conjunto de transformaciones macro estructurales derivadas, sin duda, de los grandes proyectos hegemónicos de regionalización, como el Plan Puebla Panamá y el Tratado de Libre Comercio con los Estados Unidos, suscitan nuevas preguntas de investigación en torno a sus consecuencias sobre los mercados de trabajo y, por ende, sobre las migraciones; así como otras interrogantes sobre las nuevas territorialidades del conflicto social y sus implicaciones para la empresa de nuevas batallas por la ciudadanía. Por todo lo anterior, Morales Gamboa se sitúa en un lugar relevante en el ámbito de las discusiones generadas por las migraciones. Se une, así, a ese esfuerzo para comprender, con una amplia mirada, estas nuevas realidades vividas en Centroamérica. Por lo anterior, el libro de Morales Gamboa se sitúa en un lugar relevante en el ámbito de las 
discusiones generadas por las migraciones. Se une, así, a ese esfuerzo para comprender, con una amplia mirada, estas nuevas realidades vividas en Centroamérica.
María del Carmen García Aguilar

CESMECA-UNICACH

Cuerpo académico: Política, diferencia y fronteras 